\title{
Schuhmode und Gesundheit
}

von

\author{
Dr. med. K. Sigg, Binningen
}

Leiter der Poliklinik für Venenerkrankungen

des Frauenspitals Basel

Beratender Arzt für Venenerkrankungen

am Kantonsspital in Liestal

und

Dr. med. F. Oesch, Bern

Stadtarzt in Bern

Mit 25 Abbildungen

Springer-Verlag Berlin Heidelberg GmbH 1958 
Alle Rechte, insbesondere das Recht der Ubersetzung in fremde Sprachen, vorbehalten.

Ohne ausdrückliche Genehmigung des Verlages ist es auch nicht gestattet, dieses Buch oder Teile daraus auf photomechanischem Wege (Photokopie, Mikrokopie) zu vervielfältigen.

\section{ISBN 978-3-8070-0243-9 ISBN 978-3-642-88144-2 (eBook) \\ DOI 10.1007/978-3-642-88144-2}

\section{(C) by Springer-Verlag Berlin Heidelberg 1958}

Ursprünglich erschienen bei J. F. Bergmann, München 1958.

Die Wiedergabe von Gebrauchsnamen, Handelsnamen, Warenbezeichnungen usw. in diesem Buch berechtigt auch ohne besondere Kennzeichnung nicht zu der Annahme, daß solche Namen im Sinne der Warenzeichen- und Markenschutzgesetzgebung als frei zu betrachten wären und daher von jedermann benutzt werden dürften. 


\section{Inbalt}

Einleitung . . . . . . . 5

Historischer Überblick . . . . . 7

Gesunde Füße oder Modeschuhe? 12

Diskussion . . . . . . . 34

Ratschläge . . . . . . . . 53

Literatur . . . . . . . . 55 